\title{
HOW LONG IS THE MEMORY \\ OF THE REGION LAC STOCK MARKET?
}

\author{
Paulo Alexandre ${ }^{1}$ \\ Rui Dias ${ }^{2}$ \\ Paula Heliodoro ${ }^{3}$
}

Received: July 9, 2020 / Revised: July 30, 2020 / Accepted: August 7, 2020

(C) Association of Economists and Managers of the Balkans, 2020

\begin{abstract}
Coronavirus Covid-19 is a type of outbreak that first appeared in December 2019 in the city of Wuhan, Hubei Province, China. It was declared a pandemic by the World Health Organization (WHO) on March 12, 2020. This trial aims to test the hypothesis of an efficient market, in its weak form, in the context of the global pandemic, in the financial markets of Argentina, Brazil, Chile, Colombia, Peru, Mexico. The sample comprises daily data from July 2015 to June 2020 and is divided into two sub-periods pre and during Covid-19. The purpose of this analysis was to answer whether: i) the global pandemic (Covid-19) increased synchronization in the financial markets under analysis? ii) if so, could the persistence of profitability delimit the hypothesis of portfolio diversification? The results of the Gregory-Hansen test show very significant levels of integration in the periods before and during the Covid pandemic. In addition, we found that most of the breaks in structure are in March 2020. The results of the DFA exponents show that during the pre-Covid period, the Peruvian market shows persistence, suggesting signs of inefficiency (long memories), while the Argentinean market shows anti persistence, and the remaining markets show an equilibrium trend. In addition, we found that during the COVID period the Chilean and Colombia markets show very significant signs of inefficiency, with moderate signs of in (efficiency) the Argentinean, Brazilian and Peruvian markets. In addition, we verified that the Mexican market shows signs of anti-persistence. In conclusion, the emerging markets of Latin America show, for the most part, long persistent and significant memories during the Covid pandemic outbreak, that is, they show signs of in (efficiency). The authors consider that the results achieved are of interest to investors seeking opportunities in these stock exchanges, as well as to policy makers to carry out institutional reforms in order to increase the efficiency of stock markets and promote the sustainable growth of financial markets.
\end{abstract}

Keywords: Covid-19; Market efficiency; Financial integration; Portfolio diversification.

\section{JEL Classification C58 $\cdot$ G10 $\cdot$ G11 $\cdot$ G12 $\cdot$ G14 $\cdot$ G15 $\cdot$ F30}

paulo.alexandre@esce.ips.pt

1 Polytechnic Institute of Setúbal, School of Business and Administration, ESCE, Estefanilha, 2914-503 Setúbal, Portugal

2 Institute Polytechnic of Setúbal, School of Business and Administration, ESCE, Portugal \& CEFAGE, University of Évora, Portugal

3 Polytechnic Institute of Setúbal, School of Business and Administration, ESCE, Estefanilha, 2914-503 Setúbal, Portugal 


\section{INTRODUCTION}

The Covid-19 epidemic negatively affects global trade as well as social and cultural life, including tourism, trade in goods, production and sectors such as transport. Rating agencies such as Moody's and Standard \& Poors have therefore reduced China's growth forecast for 2020. In line with all these negative effects, it seems inevitable that stock markets, economic growth and exchange rates have also been affected equally (Liu, Manzoor, Wang, Zhang and Manzoor, 2020).

Thus, the study aims to investigate the relationship between COVID-19 and the stock markets of Argentina, Brazil, Chile, Colombia, Peru, Mexico, in the period from July 2015 to June 2020. With the purpose of achieving such analysis, we intend to answer whether: i) the global pandemic (COVID-19) has increased synchronization in the financial markets under analysis? ii) if so, the persistence in yields could delimit the hypothesis of portfolio diversification? that is, we intend to test whether these financial markets have decreased their efficiency due to the pandemic outbreak. The results suggest that these regional markets show robust signs of in (efficiency), as well as very high levels of integration, which may jeopardize portfolio diversification.

This research adds two main contributions to the literature. The first contribution refers to the study of risk diversification in Latin American markets in the context of the COVID-19 outbreak pandemic. As far as we know, this is the first study that analyses these financial markets in isolation. However, there are recent studies that have analysed risk diversification, in the context of the global pandemic, namely the authors Liu, Manzoor, Wang, Zhang and Manzoor (2020) and Zeren $\&$ Hizarci (2020). However, the approach was quite different from that followed in this paper.

The second contribution is econometric in nature, as results are compared between econometric methods and mathematical models that have the possibility of evaluating correlations in the context of non-stationarity. In particular, the test of Gregory \& Hansen (1996) which demonstrates the presence of integration between financial markets with breaks in structures and, in a complementary manner to the Detrended Fluctuation Analysis (DFA) methodology, which will assess the presence or otherwise of long memories in these stock indices and test whether these markets are efficient, in their weak form.

In terms of structure, this test is organised into 5 sections. In addition to the current introduction, Section 2 presents an analysis of the Literature Review regarding articles on the assumption of efficiency in its weak form in financial markets, Section 3 describes the methodology and data, Section 4 contains the results. Section 5 presents the general conclusions of the work.

\section{LITERATURE REVIEW}

The subject of the efficient market hypothesis (EMH) has motivated several studies to analyse the implications of the market efficiency hypothesis, according to which the current price of assets reflects all available information at a given moment and the price adjusts quickly as new and unforeseen information reaches the market. The inversion to the average hypothesis, also called negative series correlation, has been interpreted as an efficient correction mechanism in developed markets and, a sign of speculative bubble in emerging financial markets (Fama and French, 1988).

Different studies have analysed the issue of market efficiency, examining the assumption of predictability of returns, through the analysis of the average reversal in financial market prices (Fama and French, 1988). When the assumptions of random walk and information efficiency are rejected, 
they cause extreme commotions in stock prices. The occurrence of these phenomena may eventually diminish the implementation of efficient portfolio diversification strategies (Malafeyev, Awasthi, S.Kambekar and Kupinskaya, 2019; Sadat and Hasan, 2019).

Sierra Suárez, Duarte Duarte and Mascareñas Pérez-Iñigo (2013), Worthington and Higgs (2013) Brazil, Chile, Colombia, Mexico, Peru and Venezuela are examined for random walks using serial correlation coefficient and runs tests, Augmented Dickey-Fuller (ADF, Duarte and Mascareñas Pérez-Iñigo (2014), Ruiz-Porras and Ruiz-Robles (2015) studied the efficiency of the markets, in their weak form, in Latin America. Sierra Suárez, Duarte Duarte and Mascareñas Pérez-Iñigo (2013) evidence that the Colombian market shows signs of inefficiency, in its weak form, showing some predictability in returns based on historical data. Worthington and Higgs (2013)Brazil, Chile, Colombia, Mexico, Peru and Venezuela are examined for random walks using serial correlation coefficient and runs tests, Augmented Dickey-Fuller (ADF analysed the financial markets of Argentina, Brazil, Chile, Colombia, Mexico, Peru and Venezuela, showing that the efficient market hypothesis is rejected. Duarte and Mascareñas Pérez-Iñigo (2014) analysed the top 5 financial markets in Latin America from January 2002 to August 2012. The authors show that the five main Latin American economies have undergone a shift from non-efficiency to efficiency in recent years, according to the following chronological order: Mexico (2007), Brazil (2008), Colombia (2008), Chile (2011) and Peru (2012). Ruiz-Porras and Ruiz-Robles (2015) analysed the return of the Mexican shares, in the period 2000-2012. The main results suggest that the Mexican stock market is inefficient in its weak form, and this efficiency has decreased since 2007.

More recently, Malafeyev, Awasthi, S.Kambekar and Kupinskaya (2019), Caporale, Gil-Alana and Poza (2020)i.e., the difference between the two logged series. Specifically, monthly, weekly and daily data on the following five European stock market indices are analysed: DAX30 (Germany, Milos, Hatiegan, Milos, Barna and Botoc (2020) have tested efficiency in several markets. Malafeyev, Awasthi, S.Kambekar and Kupinskaya (2019) studied the stock markets of China and India, showing that these stock markets do not show market efficiency in their weak form. Already Caporale, Gil-Alana and Poza (2020)i.e., the difference between the two logged series. Specifically, monthly, weekly and daily data on the following five European stock market indices are analysed: DAX30 (Germany analysed five European stock market indices: DAX30 (Germany), FTSE100 (United Kingdom), CAC40 (France), FTSE MIB40 (Italy) and IBEX35 (Spain), highlighting the presence of long memories, which could jeopardise market efficiency in its weak form. Milos, Hatiegan, Milos, Barna and Botoc (2020) examined seven stock markets in Central and Eastern Europe. The authors showed that the returns presented long-term correlations, supporting the idea that the stock markets in question were not efficient, nor had they reached the mature stage of market development.

In summary, this work aims to contribute to the provision of information to investors and regulators in international stock markets, where individual and institutional investors seek diversification benefits, as well as to help promote the implementation of policies that contribute to the efficiency of markets, in their weak form, in the context of the global pandemic (COVID-19).

\section{METHODOLOGY}

\subsection{Data}

The closing price data for the financial markets of Argentina, Brazil, Chile, Colombia, Peru and Mexico were obtained from the Thomson Reuters platform. The quotations are daily and com- 
prise the period from 1 July 2015 to 29 June 2020 and were split into two sub-periods pre and during Covid-19. Quotations are in local currency to mitigate exchange rate distortions.

Table 1. The name of countries and their indices used in this paper

\begin{tabular}{ll}
\hline Country / Region name & Index \\
\hline Argentina / América Latina & MERVAL \\
Brazil / América Latina & BOVESPA \\
Chile / América Latina & IPSA \\
Colombia / América Latina & COLCAP \\
Peru / América Latina & BVLAC \\
Mexico / América Latina & BOLSAA.MX \\
\hline
\end{tabular}

Source: Own elaboration

\subsection{Methodology}

The development of research has taken place in several stages. The characterization of the sample used was carried out using descriptive statistics. With the purpose of verifying the integration or segmentation of financial market indices in Latin America, we used the methodology of Gregory and Hansen (1996), because we're looking at a very troubled period in the financial markets. Although Hurst's exponent will not be used directly, a methodology will be applied that indirectly proposes the same information: Detrended Fluctuation Analysis (DFA). DFA is a method of analysis that examines time dependency in non-stationary data series. This technique by assuming that the time series are non-stationary avoids spurious results when the analysis focuses on the relationships of the data series in the long run. DFA has the following interpretation: $0<\alpha<0.5$ : anti persistent series; $\alpha=0.5$ series presents random walk; $0.5<\alpha<1$ persistent series.

\section{RESULTS}

Figure 1 shows the evolution of the markets, in first differences, under analysis. The sample comprises the time span from July 1, 2015 to June 29, 2020, which is a very complex period due to the understanding of the outbreak of the global pandemic (COVID-19). The yields clearly reveal the instability experienced in these markets in February, March and April.

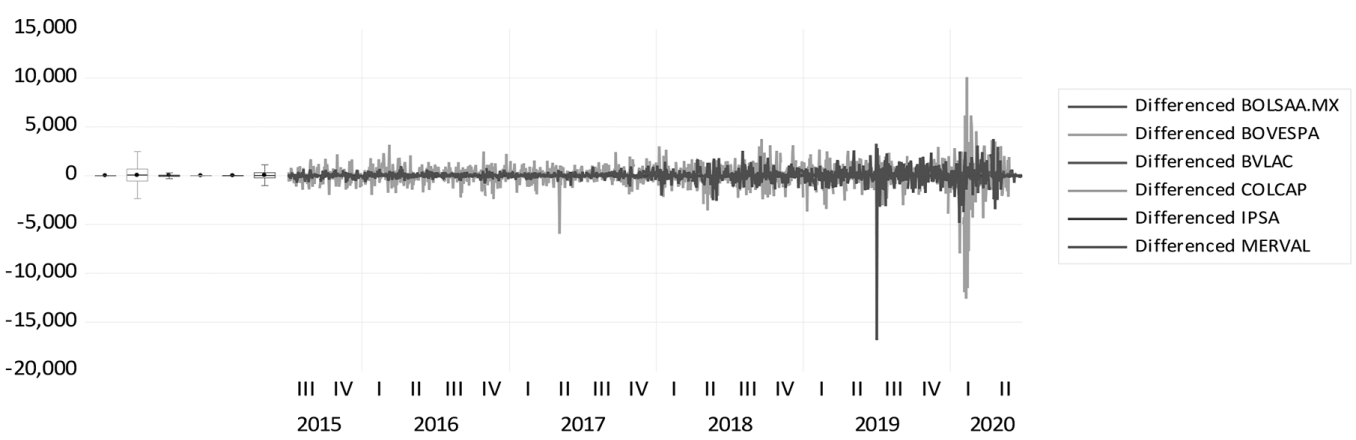

Figure 1. First differences in the evolution of the 6 financial markets in the full period Source: Own elaboration

Table 2 shows the main descriptive statistics of the financial markets under analysis. The analysis of the descriptive statistics allows us to gauge that most of the returns have positive daily aver- 
ages, except for the stock market indices of Colombia, Chile. The asymmetry characteristics are negative, except for the Mexican market. On the other hand, all the series of returns showed signs of deviation from the hypothesis of normality, given the coefficients of asymmetry and kurtosis. In the case of a normal distribution, the asymmetry coefficient takes the value zero and the kurtosis coefficient the value three. The analysed series are leptocurricular and have asymmetric tabs, so they do not follow a normal distribution.

Table 2. Descriptive statistics, return, of the 6 financial markets in the full period

\begin{tabular}{lcccc}
\hline Index & $\mathrm{N}$ & Mean & Skewness & Kurtosis \\
\hline BOLSAA.MX & 1256 & 0,000341 & 0,7382 & 11,7366 \\
BOVESPA & 1256 & 0,000485 & $-1,27211$ & 16,46721 \\
IPSA & 1256 & $-9,8 \mathrm{E}-05$ & $-2,81171$ & 47,80726 \\
COLCAP & 1256 & $-0,00035$ & $-2,10251$ & 49,04115 \\
MERVAL & 1256 & 0,000986 & $-4,30549$ & 70,90799 \\
BVLAC & 1256 & 0,000184 & $-0,98772$ & 17,92709 \\
\hline
\end{tabular}

Source: Own elaboration

Table 3 shows the results of the Gregory-Hansen test (1996), and easily detects 20 integrated market pairs (out of 30 possible) in the pre-Covid period. The Peruvian market shows 5 integrations (out of 5 possible). The Brazilian market shows 4 integrations, while the Argentina, Chile and Mexico markets show 3 integrations, the Mexican market shows 2 integrations. In the Covid period the levels of integration between the Latin American markets oscillated ( 23 out of 30 possible). The Chilean and Mexican markets rose to 5 integrations, Brazil maintained (4 integrations). The Peruvian market fell to 4 integrations, while the Colombian and Argentinean markets showed 3 and 2 integrations, respectively. In addition, we note that the breakdown of the structure is mostly in March 2020. These results are in line with the authors' studies Caporale, Gil-Alana \& Poza (2020), Milos, Hatiegan, Milos, Barna \& Botoc (2020), which show high levels of integration in the stock markets, which calls into question the diversification of portfolios in these regional markets. These evidences have important implications for individual and international investors, portfolio managers and policy makers.

Table 3. Gregory-Hansen tests, Covid period

\begin{tabular}{llcccc}
\hline Markets & t-statistic & Method & Lags & Break Date & Results \\
\hline BOLSAA.MX / BOVESPA & $-5.41^{* *}$ & Trend & 0 & $09 / 03 / 2020$ & Integration \\
BOLSAA.MX / IPSA & $-4.98^{* *}$ & Trend & 0 & $09 / 03 / 2020$ & Integration \\
BOLSAA.MX / COLCAP & $-5.32^{* *}$ & Trend & 3 & $09 / 03 / 2020$ & Integration \\
BOLSAA.MX / MERVAL & $-5.04^{* * *}$ & Trend & 0 & $09 / 03 / 2020$ & Integration \\
BOLSAA.MX / BVLAC & $-5.20^{* *}$ & Trend & 5 & $17 / 04 / 2020$ & Integration \\
BOVESPA / BOLSAA.MX & $-5.00^{* *}$ & Trend & 0 & $31 / 01 / 2020$ & Integration \\
BOVESPA / IPSA & $-5.47^{* * *}$ & Trend & 0 & $31 / 01 / 2020$ & Integration \\
BOVESPA / COLCAP & $-5.67^{* * *}$ & Trend & 0 & $31 / 01 / 2020$ & Integration \\
BOVESPA / MERVAL & $-5.67^{* * *}$ & Trend & 0 & $06 / 02 / 2020$ & Integration \\
BVLAC / BOLSAA.MX & $-5.03^{* *}$ & Regime & 0 & $05 / 03 / 2020$ & Integration \\
BVLAC / BOVESPA & $-5.20^{* *}$ & Regime & 4 & $10 / 03 / 2020$ & Integration \\
BVLAC / COLCAP & $-5.35^{* *}$ & Regime & 2 & $05 / 03 / 2020$ & Integration \\
\hline BVLAC / IPSA & $-4.78^{*}$ & Regime & 3 & $05 / 03 / 2020$ & Integration \\
IPSA / BOLSAA.MX & $-5,72^{* * *}$ & Trend & 0 & $12 / 05 / 2020$ & Integration
\end{tabular}




\begin{tabular}{llcccc}
\hline Markets & t-statistic & Method & Lags & Break Date & Results \\
\hline IPSA / BOVESPA & $-6.28^{* * *}$ & Trend & 0 & $12 / 05 / 2020$ & Integration \\
IPSA / COLCAP & $-5.04^{* *}$ & Trend & 0 & $12 / 05 / 2020$ & Integration \\
IPSA / MERVAL & $-5.18^{* *}$ & Trend & 2 & $04 / 05 / 2020$ & Integration \\
IPSA / BVLAC & $-5,33^{* *}$ & Trend & 3 & $12 / 05 / 2020$ & Integration \\
COLCAP / BOVESPA & $-6.32^{* * *}$ & Trend & 3 & $15 / 01 / 2020$ & Integration \\
COLCAP / IPSA & $-5.60^{* * *}$ & Trend & 3 & $15 / 01 / 2020$ & Integration \\
COLCAP / MERVAL & $-5.44^{* *}$ & Trend & 1 & $11 / 03 / 2020$ & Integration \\
MERVAL / COLCAP & $-6.51^{* * *}$ & Trend & 0 & $11 / 03 / 2020$ & Integration \\
MERVAL / BVLAC & $-6.44^{* * *}$ & Trend & 0 & $23 / 01 / 2020$ & Integration \\
\hline
\end{tabular}

Source: Own elaboration

Notes: The critical values are found in Gregory and Hansen (1996). The asterisks ***, **, * indicate statistical significance at $1 \%, 5 \%$ and $10 \%$, respectively

In table 4 we can see the results of the DFA exponents, in both subperiods. We verified that during the pre-Covid period, the Peruvian market presents persistence, suggesting signs of inefficiency (long memories), while the Argentinean market presents anti persistence, and the remaining markets show an equilibrium trend. In addition, we found that during the COVID period the Chilean and Colombia markets show very significant signs of inefficiency, with moderate signs in Argentina, Brazil and Peru. Additionally, we can see that the Mexican market shows signs of anti-persistence. These results are in line with the authors' evidence Aggarwal (2018), Rehman, Chhapra, Kashif and Rehan (2018), Malafeyev, Awasthi, S.Kambekar and Kupinskaya (2019), which document that markets are (in) efficient in their weak form and that portfolio diversification may be questioned.

Table 4. DFA results. The hypotheses are $H_{0}: \alpha=0.5$ and $H_{1}: \alpha \neq 0.5$

\begin{tabular}{ccc}
\hline Stock market & DFA exponent (before crisis) & DFA exponent (crisis period) \\
\hline BOLSAA.MX & $0.49 \cong 0,0033\left(R^{2}=0,99\right)$ & $0.39 \cong 0.0210\left(R^{2}=0,97\right)$ \\
BOVESPA & $0.49 \cong 0.0044\left(R^{2}=0,99\right)$ & $0.53 \cong 0.0248\left(R^{2}=0,99\right)$ \\
BVLAC & $0.55 \cong 0.0010\left(R^{2}=0,99\right)$ & $0.54 \cong 0.0131\left(R^{2}=0,98\right)$ \\
COLCAP & $0.52 \cong 0.0015\left(R^{2}=0,99\right)$ & $0.74 \cong 0.0003\left(R^{2}=0,99\right)$ \\
IPSA & $0.51 \cong 0.0065\left(R^{2}=0,99\right)$ & $0.64 \cong 0.0127\left(R^{2}=0,98\right)$ \\
MERVAL & $0.41 \cong 0.0022\left(R^{2}=0,97\right)$ & $0.54 \cong 0.0050\left(R^{2}=0,99\right)$ \\
\hline
\end{tabular}

Source: Own elaboration

\section{CONCLUSION}

The general conclusion to be retained and, supported by the results obtained, through tests performed with econometric models, demonstrates that the global pandemic has a significant impact on the memory properties of financial market indices in Latin America. We found that the level of financial integration is very significant in these markets, calling into question the implementation of efficient portfolio diversification strategies. These markets also prove to be inefficient in their weak form due to the high levels of arbitrage identified. In conclusion, we consider that these evidences are relevant for policy makers and investors in relation to regional development policies and portfolio diversification strategies in these regional markets. 


\section{REFERENCES}

Aggarwal, D. (2018). Random walk model and asymmetric effect in Korean composite stock price index. Afro-Asian J. of Finance and Accounting. https://doi.org/10.1504/aajfa.2018.10009906

Caporale, G. M., Gil-Alana, L. A., \& Poza, C. (2020). High and low prices and the range in the European stock markets: A long-memory approach. Research in International Business and Finance. https://doi.org/10.1016/j.ribaf.2019.101126

Duarte Duarte, J. B., \& Mascareñas Pérez-Iñigo, J. M. (2014). Comprobación de la eficiencia débil en los principales mercados financieros latinoamericanos. Estudios Gerenciales. https://oi. org/10.1016/j.estger.2014.05.005

Fama, E. F., \& French, K. R. (1988). Dividend yields and expected stock returns. Journal of Financial Economics. https://doi.org/10.1016/0304-405X(88)90020-7

Gregory, A. W., \& Hansen, B. E. (1996). Residual-based tests for cointegration in models with regime shifts. Journal of Econometrics, 70(1), 99-126. https://doi.org/10.1016/0304-4076(69)41685-7

Lawrence H. Summers. (1986). Does the stock market rationally reflect fundamental values. The Journal of Finance. https://doi.org/10.2307/2328487

Liu, H., Manzoor, A., Wang, C., Zhang, L., \& Manzoor, Z. (2020). The COVID-19 outbreak and affected countries stock markets response. International Journal of Environmental Research and Public Health. https://doi.org/10.3390/ijerph17082800

Malafeyev, O., Awasthi, A., S.Kambekar, K., \& Kupinskaya, A. (2019). Random Walks and Market Efficiency in Chinese and Indian Equity Markets. Statistics, Optimization \& Information Computing. https://doi.org/10.19139/soic.v7il.499

Milos, L. R., Hatiegan, C., Milos, M. C., Barna, F. M., \& Botoc, C. (2020). Multifractal detrended fluctuation analysis (MF-DFA) of stock market indexes. Empirical evidence from seven central and eastern European markets. Sustainability (Switzerland). https://doi.org/10.3390/su12020535

Rehman, S., Chhapra, I. U., Kashif, M., \& Rehan, R. (2018). Are Stock Prices a Random Walk? An Empirical Evidence of Asian Stock Markets. Etikonomi. https://doi.org/10.15408/etk.v17i2.7102

Ruiz-Porras, A., \& Ruiz-Robles, B. (2015). La hipótesis de eficiencia y la modelación de series bursátiles mexicanas: un análisis multivariado. Economía Informa. https://doi.org/10.1016/ s0185-0849(15)30003-7

Sierra Suárez, K. J., Duarte Duarte, J. B., \& Mascareñas Pérez-Iñigo, J. M. (2013). Comprobación del Comportamiento Caótico en Bolsa de Valores de Colombia. Revista Estrategia Organizacional. https://doi.org/10.22490/25392786.1480

Worthington, A. C., \& Higgs, H. (2013). Tests of random walks and market efficiency in Latin American stock markets: An empirical note. Pathogens and Global Health. https://doi.org/10.1179/20 4777213X13869290853977

Zeren, F., \& Hizarci, A. (2020). The Impact of Covid-19 Coronavirus on Stock Markets: Evidence from Selected Countries. Muhasebe ve Finans Incelemeleri Dergisi. https://doi.org/10.32951/ mufider.706159 